\title{
Perencanaan Pengembangan Prasarana Kawasan Ekowisata Situ Gede Kota Bogor
}

\section{(Infrastructure Development Planning of Situ Gede Ecotourism Area)}

\author{
Muhammad Fatahudin ${ }^{*}$, M. Yanuar Jarwadi Purwanto ${ }^{1}$, dan Maulana Ibrahim Rau ${ }^{1}$ \\ ${ }^{1}$ Departemen Teknik Sipil dan Lingkungan, Fakultas Teknologi Pertanian, Institut Pertanian Bogor. \\ Jl. Raya Dramaga, Kampus IPB Dramaga, PO BOX 220, Bogor, Jawa Barat, Indonesia \\ *Penulis Korespondensi: muhammadfatahudin98@gmail.com
}

\begin{abstract}
Situ Gede area includes a local protection area, functioning as a water catchment area and protected area that will be developed into an ecotourism area based on RTRW and RTBL Situ Gede area and CIFOR fiscal year 2014. The research was conducted to evaluate the existing infrastructure and to make the planning of its development special on environmental roads, waste systems, and parking buildings. The research method begins with the creation of the basic map of Situ Gede area, the retrieval of existing data using secondary data, infrastructure planning in the form of environmental roads, waste management system, and parking building planning, and the creation of infrastructure development planning map Situ Gede area as an external expected from this research. Planning to observe the conservation aspects of water resources by conducting zoning utilization. The zoning arrangement was conducted to provide protection, use, and control of existing resources, especially the creation of a lake boundary of $50 \mathrm{~m}$ wide from the body.
\end{abstract}

Keywords: Ecotourism area, Existing infrastructure, Infrastructure planning, Water resource conservation.

\section{PENDAHULUAN}

Pembangunan ekonomi daerah merupakan kolaborasi yang efektif antara masyarakat dan pemerintah dalam memanfaatkan sumberdaya yang ada. Dalam konteks ini pemerintah sebagai regulator memiliki peran yang sangat strategis dalam mengupayakan kesempatan bagi masyarakat lokal untuk berpartisipasi penuh dalam aktivitas ekonomi (Satria 2009). Salah satu upaya dalam pengembangan ekonomi daerah adalah pemanfaatan sumberdaya lokal secara optimal dengan mengembangkan pariwisata berbasis ekowisata. Dalam hal ini wisata yang dilakukan memiliki bagian yang tidak terpisahkan dengan upaya-upaya konservasi, pemberdayaan ekonomi lokal dan mendorong respek yang lebih tinggi terhadap perbedaan kultur atau budaya. Hal inilah yang mendasari perbedaan antara konsep ekowisata dengan model wisata konvensional yang telah ada sebelumnya (Satria 2009).

Pengembangan ekowisata berbasis masyarakat merupakan sebuah usaha yang menitikberatkan peran aktif masyarakat. Hal tersebut berdasar pada kenyataan bahwa masyarakat sekitar memiliki pengetahuan tentang alam dan nilai jual sebagai daya tarik wisata, sehingga melibatkan masyarakat menjadi hal mutlak untuk keberlangsungan ekowisata tersebut. Pola ekowisata berbasis masyarakat mengakui hak masyarakat lokal dalam mengelola kegiatan wisata di kawasan yang mereka miliki secara adat ataupun 
sebagai pengelola. Dengan adanya pola ekowisata berbasis masyarakat bukan berarti masyarakat akan menjalankan usaha ekowisata sendiri (Hijriati dan Mardiana 2014).

Dalam memajukan suatu wisata diperlukan daya dukung lain yang begitu penting yaitu sarana dan prasarana berupa infrastruktur penunjang. Sarana dan prasarana kepariwisataan sesungguhnya merupakan kebutuhan wisatawan yang perlu disiapkan atau disediakan dalam mengembangkan industri pariwisata. Prasarana (infrastruktur) adalah semua fasilitas yang memungkinkan proses perekonomian dapat berjalan dengan lancar sedemikian rupa, sehingga dapat memudahkan manusia untuk memenuhi kebutuhannya. Jadi fungsinya adalah melengkapi sarana kepariwisataan, sehingga dapat memberikan pelayanansebagaimana mestinya (Yoety 1996 dalam Agusbushro et al 2015).

Berdasarkan Peraturan Daerah Kota Bogor No. 8 (PemKot Bogor2011) daerah Bogor Barat termasuk kedalam Wilayah Pelayanan B (WP B) yang memiliki mandat diantaranya sebagai berikut:
1. Perlindungan kawasan lindung Situ Gede dan hutan kota CIFOR dari gangguan kegiatan yang dapat mengurangi fungsi lindung kawasan ini. Mempertahankan luasan lahan pertanian kota.

2. Mengarahkan dan mengendalikan perkembangan perumahan agar tetap berkepadatan sedang dan rendah.

3. Mengembangkan RTH sesuai hirarki pelayanan.

Wilayah perencanaan yang akan dikembangkan menjadi kawasan ekowisata adalah Situ Gede Kota Bogor. Menurut Hatmoko et al (2012), situ adalah sejumlah air (tawar atau asin) yang terakumulasi di suatu tempat yang cukup luas, dan dapat terbentuk karena mencairnya gletser, aliran sungai, atau karena adanya mata air.

\section{METODOLOGI}

Penelitian dilaksanakan bulan April hingga Juni 2020. Lokasi penelitian berada di Situ Gede Kecamatan Bogor Barat Kota Bogor. Peta lokasi penelitian disajikan pada Gambar 1.

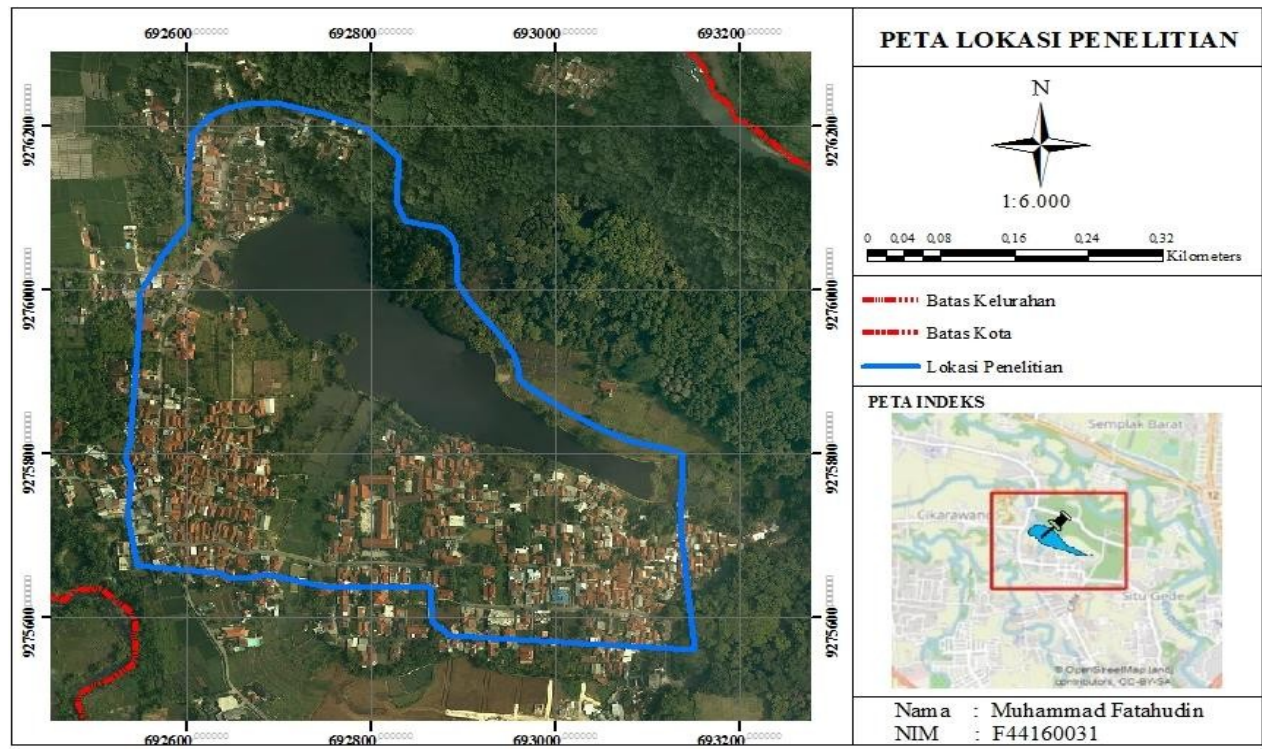

Gambar 1 Peta Lokasi Penelitian 
Data yang digunakan pada penelitian ini merupakan data primer dan data sekunder. Data primer didapatkan berdasarkan observasi di lapangan dan data sekunder yang digunakan berupa Rencana Tata Ruang dan Wilayah Kota Bogor Tahun 2011-2031, foto udara Kelurahan Situ Gede yang berasal dari Badan Informasi Geospasial, dan beberapa data sekunder ditunjang oleh penelitian sebelumnya serta penelitian di tempat lain yang memiliki karakteristik lokasi hampir sama. Peralatan yang digunakan dalam penelitian ini adalah global positioning system (GPS), dan seperangkat laptop yang dilengkapi dengan Microsoft Office, ArcGIS 10.4.1 dan Google Earth.

Penelitian dilakukan dalam beberapa tahapan, sebagai berikut:

1. Pengambilan data

Dalam penelitian ini digunakan data sekunder. Pengumpulan data dilakukan melalui studi pustaka, dan berbagai dokumen resmi dari instansi terkait.

2. Identifikasi prasarana eksisting Identifikasi prasarana eksisting dilakukan dengan observasi lapangan, melakukan pencatatan dan dokumentasi pada prasarana yang terdapat di lokasi. Selain itu, identifikasi juga didukung dengan data sekunder berupa studi pustaka terkait penelitian yang dilakukan sebelumnya di lokasi.

3. Pembuatan Peta Dasar

Penelitian Tahap ini membuat peta dasar dengan menggunakan citra dari hasil foto udara pesawat tak berawak (drone) , karena area yang digunakan dalam penelitian tidak begitu luas. Kemudian pada citra yang sudah didapatkan dilakukan orthorektifikasi topografi yang berasal dari hasil unduh di website DEMNAS, lalu citra di overlay dengan data administrasi, jaringan jalan, dan jaringan sungai. Selain membuat peta dasar secara mandiri, pada tahap ini juga membandingkan dengan peta dasar dari foto udara se-kota Bogor yang telah dilengkapi dengan data atribut berasal dari Badan Informasi Geospasial (BIG).

4. Perencanaan Prasarana Penunjang Ekowisata

a. Jalan

Perencanaan mengacu pada beberapa ketentuan berikut:

- Undang-undang Nomor 38

Tahun 2004 (PRI 2004)

- SNI 03-1733-2004 (BSN 2004)

- RSNI T-14-2004 (BSN 2004)

b. Fasilitas Tempat Parkir

Berdasarkan Keputusan

Direktur Jenderal Perhubungan

Darat Nomor

272/HK.105/DRJD/96 (DirjenPD 1996), fasilitas parkir adalah lokasi yang ditentukan sebagai pemberhentian kendaraan yang tidak bersifat sementara untuk melakukan kegiatan pada suatu kurun waktu yang dinyatakan dengan satuan ruang parkir (SRP). SRP adalah ukuran luas efektif untuk meletakkan kendaraan (mobil penumpang, bus/truk, sepeda motor), termasuk ruang bebas dan lebar buka pintu. Ketentuan SRP pada Tabel 1 berikut: 
Tabel 1. Satuan Ruang Parkir

\begin{tabular}{cc}
\hline $\begin{array}{c}\text { Luas Areal } \\
\left(100 \mathrm{~m}^{2}\right)\end{array}$ & $\begin{array}{c}\text { Kebutuhan } \\
(\text { SRP })\end{array}$ \\
\hline 50 & 103 \\
100 & 109 \\
150 & 115 \\
200 & 122 \\
400 & 146 \\
800 & 196 \\
1600 & 295 \\
3200 & 494 \\
6400 & 892 \\
\hline
\end{tabular}

Sumber : DirjenPD (1996)

5. Pembuatan Peta Rencana Pengembangan Prasarana Kawasan Ekowisata

Pada tahap ini, semua data yang telah didapatkan dan dianalisis kemudian divisualisasikan ke dalam bentuk peta perencanaan dengan melakukan digitasi peta dasar menggunakan perangkat lunak ArcGIS sesuai dengan analisis dan data atribut peta yang digunakan.

\section{HASIL DAN PEMBAHASAN}

\section{Kondisi Eksisting Kawasan Situ Gede}

\section{Jenis Pemanfaatan Kawasan Situ Gede}

Berdasarkan Badan Pengelolaan Sumber Air Bogor, Departemen Pekerjaan Umum (2008), kawasan Situ Gede mempunyai manfaat yang beragam diantaranya digunakan sebagai irigasi untuk lahan pertanian, mengairi kolamkolam ikan dengan luas \pm 175 Ha yang trersebar di dua desa yaitu Desa Situ Gede dan Desa Cikarawang, serta digunakan untuk mengairi dua situ lain yang berada di sebelah hilir yaitu Situ Panjang dan Situ Burung dengan panjang saluran mencapai $2.500 \mathrm{~m}$. Selain beberapa fungsi tersebut, Situ Gede juga memiliki manfaat sebagai pengendali banjir, sumber air baku untuk masyarakat, lokasi penelitian sumberdaya air, habitat biota air, dan menjadi lokasi wisata air. Adapun tiga jenis manfaat yang terjadi di Situ Gede dan dapat dirasakan secara langsung yaitu sebagai sumber air irigasi pertanian, wahana wisata air, dan pemanfaatan untuk pemancingan.

Dalam pemanfaatan Situ Gede sebagai wahana wisata air perlu dilakukan peninjauan dan perencanaan sarana prasarana agar dapat menunjang setiap atraksi wisata yang ada. Sarana prasarana tersebut dapat berupa penyediaan lahan untuk parkir kendaraan, dan pelebaran jalan lingkungan sehingga mempermudah akses kendaraan untuk masuk dankeluar kawasan. Berdasarkan penelitian yang telah dilakukan Widyaningsih (2015), menyatakan bahwa pengelolaan Situ Gede untuk kegiatan wahana wisata air belum optimal.

\section{Kondisi Jalan}

Berdasarkan hasil pengukuran lebar badan jalan pada beberapa titik menggunakan bantuan software ArcGIS memiliki rata-rata lebar sebesar $5 \mathrm{~m}$, walaupun pada beberapa ruas memiliki lebar badan jalan sekitar $8 \mathrm{~m}$, hasil pengukuran dapat dilihat pada lampiran 5. Apabila mengacu kepada jenis jalan menurut fungsinya berdasar pada Peraturan Pemerintah Nomor 34 (PRI 2006) , maka ruas jalan di sekitar kawasan ekowisata Situ Gede termasuk ke dalam jalan lingkungan primer.

Jalan Rawajaha-jalan alternatif kampus IPB Dramaga disebut jalan lingkungan primer selain memiliki dimensi seperti disebutkan diatas, karena jalan tersebut menghubungkan antar desa/kelurahan. Berikut merupakan ruas jalan Situ Gede : 


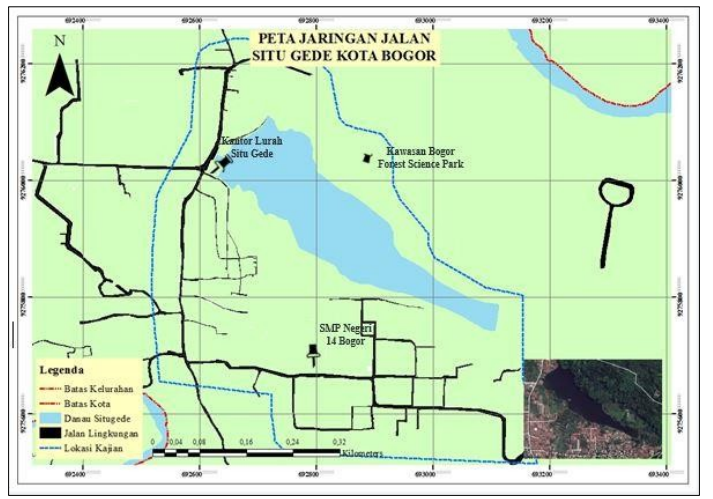

Gambar 2. Jaringan Jalan Kawasan Ekowisata Situ Gede

\section{Tempat Parkir}

Fasilitas parkir menjadi salah satu prasarana yang wajib ada di tempat wisata, sehingga keberadaannya harus dikelola dengan baik agar tempat wisata tersebut tetap teratur dan kondusif. Fasilitas tempat parkir yang ada di kawasan Situ Gede masih sangat t'erbatas dan belum tertata dengan baik, tidak ada pengkategorian jenis kendaraan yang dapat parkir di tempat tersebut. Tempat parkir berupa lapangan beraspal terdapat di samping kantor Kelurahan Situ Gede dengan dimensi 17 $\mathrm{m} \times 10 \mathrm{~m}$, dan menjadi satu-satunya lokasi resmi yang diperuntukkan untuk parkir kendaraan. Dengan adanya jalan setapak yang menggunakan paving block di samping situ, menjadikan para pemancing dapat memasuki kawasan situ dengan membawa kendaraan terkhusus sepeda motor dan memarkirkannya secara sembarangan di samping situ tersebut. Adapun lokasi tempat parkir di Situ Gede ditunjukkan pada gambar 3 di bawah ini :

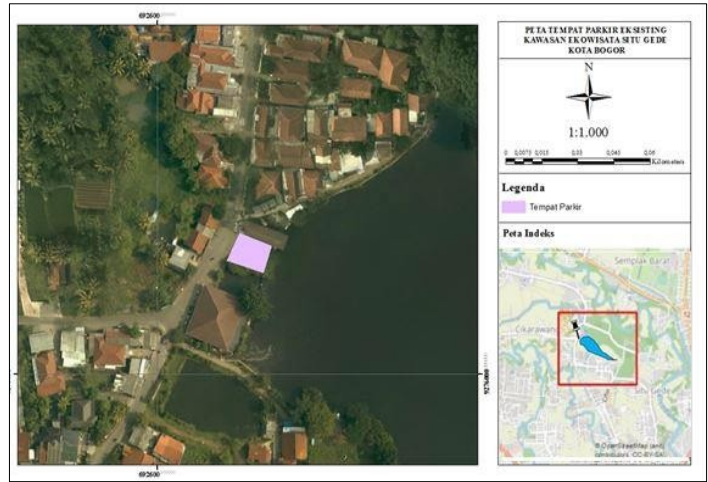

Gambar 3. Area Parkir

\section{Perencanaan Prasarana Pendukung Kawasan Ekowisata Situ Gede}

Berdasarkan peta eksisting kawasan ekowisata Situ Gede, maka sebelum melakukan perencanaan mengenai perbaikan prasarana pendukung ekowisata harus dilakukan pembuatan zonasi kawasan. Hal tersebut dimaksudkan agar kegiatan perlindungan, penggunaan, dan pengendalian atas sumber daya yang ada pada danau dapat dilaksanakan sesuai tujuannya. Menurut Peraturan Menteri Pekerjaan Umum dan Perumahan Rakyat Nomor 28/PRT/M/2015 (PermenPUPR 2015), jarak zona penyangga / garis sempadan danau paling sedikit $50 \mathrm{~m}$ dari tepi badan danau.

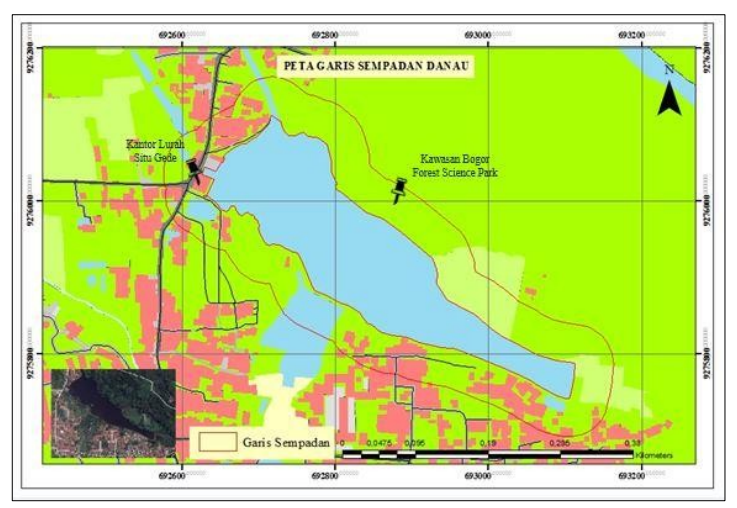

Gambar 4. Sempadan Danau

Berdasarkan gambar 4 diatas dapat dilihat bahwa harus dilakukan penataan kembali, karena di zona 
penyangga atau zona sempadan danau tersebut terdapat beberapa bangunan dan jalan lingkungan yang secara langsung dapat memberi dampak kepada ekosistem dari Situ Gede. Bangunan dan jalan lingkungan yang terdapat di dalam garis jangkauan tersebut harus direlokasi, sehingga bagian sempadan tersebut menjadi zona hijau seperti bagian utara Situ Gede. Perencanaan pembangunan prasarana pendukung ekowisata harus memperhatikan faktor tersebut sehingga tujuan konservasi dapat tercapai.

Berdasarkan Peraturan Menteri Pekerjaan Umum dan Perumahan Rakyat No. 28/PRT/M/2015

(PermenPUPR 2015), sempadan danau hanya dapat dimanfaatkan untuk kegiatan dan bangunan tertentu. Kegiatan-kegiatan tersebut diantaranya penelitian dan pengembangan ilmu pengetahuan, pariwisata, olahraga, dan aktivitas budaya dan keagamaan. Adapun bangunan yang diperbolehkan diantaranya adalah bangunan prasarana sumber daya air, jalan akses, jembatan, dermaga, jalur pipa gas dan air minum, rentangan kabel listrik dan telekomunikasi, prsarana pariwisata, olahraga, keagamaan, prasarana dan sarana sanitasi, dan bangunan ketenagalistrikan. Selain pembatasan tersebut, pada sempadan danau dilarang untuk mengubah letak tepi danau, membuang limbah, menggembala ternak, dan mengubah aliran masuk atau keluar danau.

\section{Perencanaan Jalan}

Perencanaan jalan ini berbanding lurus dengan perencanaan fasilitas gedung parkir karena berkaitan erat dengan jenis kendaraan yang akan masuk/keluar ke lokasi. Berdasarkan tabel 5 pengunjung Situ Gede lebih banyak menggunakan kendaraan pribadi, karena selain praktis juga menyesuaikan dengan kondisi eksisting jalan yang tidak terlalu lebar. Perencanaan jalan lingkungan disesuaikan dengan jenis kendaraan high volume yang direncanakan dapat memasuki kawasan wisata Situ Gede. Penentuan kriteria desain dan standar perancangan geometrik jalan dilakukan dengan kajian spesifikasi jalan rencana pada acuan dan ketentuan yang berlaku. Spesifikasi umum jalan lingkungan yang direncanakan terdapat pada tabel 2 berikut :

Tabel 2. Spesifikasi Umum

\begin{tabular}{ll}
\hline \multicolumn{1}{c}{ Indikator } & \multicolumn{1}{c}{ Keterangan } \\
\hline Fungsi Jalan & Jalan Lokal \\
Tipe Jalan & 2/2 UD \\
Status Jalan & Jalan \\
& Perkotaan \\
Klasifikasi Medan & Datar \\
Panjang Trase & $1,4 \mathrm{~km}$ \\
\hline
\end{tabular}

Sumber : Penulis, 2020.

Dari tabel 2 tersebut dapat dilihat bahwa jalan yang direncanakan berfungsi sebagai jalan lokal. Berdasarkan Undang-undang No. 38 Tahun 2004 (PRI 2004), jalan lingkungan termasuk kedalam jenisjalan umum berfungsi untuk melayani angkutan setempat dengan ciri perjalanan jarak dekat, kecepatan ratarata rendah, dan jumlah jalan masuk tidak dibatasi. Tipe jalan direncanakan memiliki dua jalur dan dua lajur tidak terbagi, hanya dibatasi oleh garis median jalan. Hal tersebut dipertimbangkan guna meminimalkan lahan yang digunakan, mengingat kepadatan penduduk dan tata guna lahan pada lokasi cukup padat.

Perencanaan jalan berikutnya merupakan penentuan kriteria geometri yang sesuai dengan spesifikasi umum yang telah disebut di atas. Dalam perencanaan geometri jalan dilakukan dengan melakukan kajian pada acuan 
dan ketentuan yang berlaku. Kriteria geometri yang ditunjukkan pada tabel 3 dibawah ini menggunakan acuan RSNI T-14-2004 (BSN 2004) tentang rencana geometerik jalan perkotaan. Kriteria geometri sebagai berikut:

Tabel 3. Kriteria Geometri Jalan Rencana

\begin{tabular}{|c|c|c|c|}
\hline No & Parameter Geometrik & Kriteria & Satuan \\
\hline 1 & Kecepatan rencana & 40 & $\mathrm{~km} / \mathrm{jam}$ \\
\hline \multirow{5}{*}{2} & Potongan melintang & & \\
\hline & Lebar lajur & 3.6 & $\mathrm{~m}$ \\
\hline & Lebar bahu & 0.5 & $\mathrm{~m}$ \\
\hline & Kemiringan melintang & 3 & $\%$ \\
\hline & Trotoar & 1.5 & $\mathrm{~m}$ \\
\hline \multirow{3}{*}{3} & Jarak pandang & & \\
\hline & Jarak pandang henti & 50 & $\mathrm{~m}$ \\
\hline & Jarak pandang menyiap & 121 & $\mathrm{~m}$ \\
\hline \multirow{5}{*}{4} & Alinyemen horizontal & & \\
\hline & Panjang tikungan minimum & 70 & $\mathrm{~m}$ \\
\hline & Superelevasi maksimum & 6 & $\%$ \\
\hline & Jari-jari tikungan minimum & 55 & $\mathrm{~m}$ \\
\hline & $\begin{array}{l}\text { Panjang lengkungan } \\
\text { peralihan minimum }\end{array}$ & 22 & $\mathrm{~m}$ \\
\hline \multirow{5}{*}{5} & Alinyemen vertikal & & \\
\hline & Landai maksimum & - & - \\
\hline & Panjang lengkung vertical: & & \\
\hline & - cembung & 4 & $\mathrm{~K}$ \\
\hline & - $\quad$ cekung & 9 & $\mathrm{~K}$ \\
\hline
\end{tabular}

Dengan jenis jalan lokal dan klasifikasi medan jalan datar, kecepatan minimum rencana berada di rentang 30 $50 \mathrm{~km} / \mathrm{jam}$ sesuai dengan tabel 4 dibawah ini dan dipilih kecepatan rencana $40 \mathrm{~km} / \mathrm{jam}$. Potonganmelintang jalan diilustrasikan pada gambar berikut:

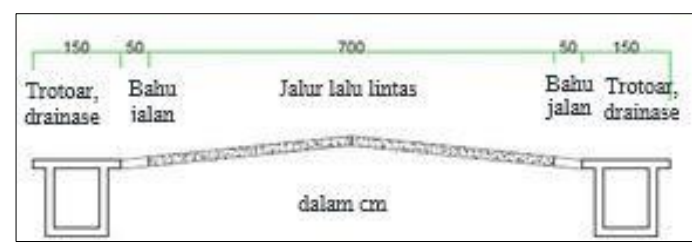

Gambar 5. Potongan Melintang Jalan

Potongan melintang jalan pada gambar tersebut memiliki lebar lajur sesuai tabel 7 direncanakan 3,6 m, atau menurut Pasal 10 ayat 3 Undang-undang No. 38 Tahun 2004 (PRI 2004) jalan dengan dua lajur tidak terbagi minimum memiliki lebar $7 \mathrm{~m}$. Lebar bahu jalan direncanakan $0,5 \mathrm{~m}$, dan kemiringan melintang jalan 3\% dengan rencana perkerasan lentur (fleksible pavement). Pada tabel 6 di acuan dijelaskan bahwa tipe jalan 2 lajur 2 arah tak terbagi disarankan dilengkapi dengan trotoar, maka lebar trotoar direncanakan sebesar $1,5 \mathrm{~m}$.

\section{Penerapan Drainase Green, Smart, dan Partisipatif pada Jalan Rencana}

Drainase merupakan prasarana yang berfungsi untuk mengalirkan kelebihan air hujan pada permukaan dari satu tempat menuju tempat lainnya (Dewi et al 2014 dalam Sadewa dan Sutoyo 2018).

Dalam meminimalisir dampak banjir yang disebabkan air meluap dari saluran drainase akibat adanya sedimentasi, maka diperlukan sebuah alat yang dapat digunakan untuk memantau setinggi apa sedimen yang terjadi pada saluran. Seperti gambar berikut:

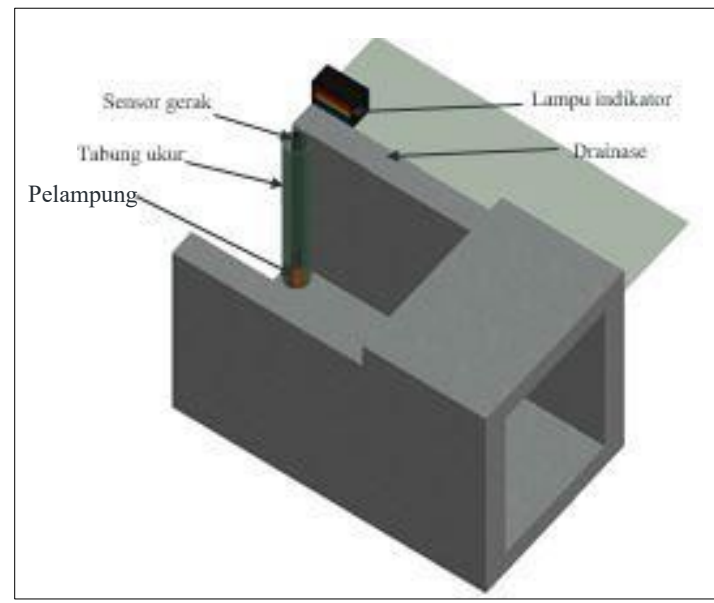

Gambar 6. Indikator Sedimentasi

Gambar 6 tersebut merupakan alat yang direncanakan dapat digunakan sebagai indikator seberapa besar sedimen yang terjadi pada saluran drainase. Indikator sedimen tersebut 
terdiri dari beberapa bagian, yaitu tabung pengukur, pelampung, sensor gerak, dan lampu indikator. Tabung pengukur memiliki lubang di bagian samping untuk mengukur sedimen dan ketinggian aliran air pada drainase. Kemudian pelampung berfungsi sebagai indikator gerak, bekerja naik dan turun sesuai dengan kondisi air dan sedimen yang terjadi. Lalu sensor gerak berfungsi untuk menangkap gerakan pelampung yang selajutnya ditransmisikan kelampu indikator, dan lampu indikator terdiri dari 5 level warna sesuai dengan kondisi yang terjadi. Keterangan dari setiap warna lampu indikator sebagai berikut:

- biru : sedimentasi 0-20\%

- hijau : sedimentasi 20-40\%

- $\quad$ kuning : sedimentasi 40-60\%

- coklat : sedimentasi $60-80 \%$

- merah : sedimentasi 100\%

Konsep green pada drainase ditunjukkan dengan penggunaan drainase dibawah trotoar, sehingga pembangunan saluran drainase tidak mengorbankan lahan yang lain. Kemudian, konsep smart pada drainase ditunjukkan dengan penggunaan alat indikator pemantau sedimen. Sehingga apabila endapan telah melewati ambang batas maksimum, maka indikator warna akan menyala melalui sinyal yang ditransmisikan dari bagian sensor gerak. Konsep partisipatif ditunjukkan dengan kepedulian masyarakat terhadap kondisi endapan yang terjadi pada saluran drainase, indikator pemantau sedimen dapat dibaca dengan mudah oleh setiap orang sehingga untuk penanganan sedimen itu sendiri tidak harus langsung oleh pemerintah.
Tabel 4. Biaya Pembuatan Alat

\begin{tabular}{|c|c|c|c|c|c|}
\hline No & Jenis Alat & Unit & $\begin{array}{c}\text { Harga } \\
(\mathrm{Rp})\end{array}$ & $\begin{array}{l}\text { Total } \\
(\mathrm{Rp}) \\
\end{array}$ & Sumber \\
\hline 1 & $\begin{array}{l}\text { Sensor } \\
\text { Gerak PIR }\end{array}$ & 5 & 70.000 & 350.000 & Market place \\
\hline 2 & Tabung & 1 & 500.000 & 500.000 & Penyesuaian \\
\hline 3 & $\begin{array}{l}\text { Lampu } \\
\text { Indikator }\end{array}$ & 5 & 500.000 & 500.000 & Penyesuaian \\
\hline 4 & $\begin{array}{l}\text { Box } \\
\text { Lampu } \\
\text { Indikator }\end{array}$ & 1 & 150.000 & 150.000 & Penyesuaian \\
\hline 5 & Pelampung & 1 & 30.000 & 50.000 & Peneyesuaian \\
\hline \multicolumn{4}{|c|}{ Total biaya } & 1.550 .000 & \\
\hline
\end{tabular}

\section{Perencanaan Gedung Parkir}

Kebutuhan akan ruang parkir berbanding lurus dengan luas lahan dan jenis aktivitas pada suatu kawasan. Berdasarkan tabel 1 diatas, maka kebutuhan ruang parkir kawasan Situ Gede yang memiliki luas $62.000 \mathrm{~m}^{2}$ ditunjukkan oleh gambar 7 berikut:

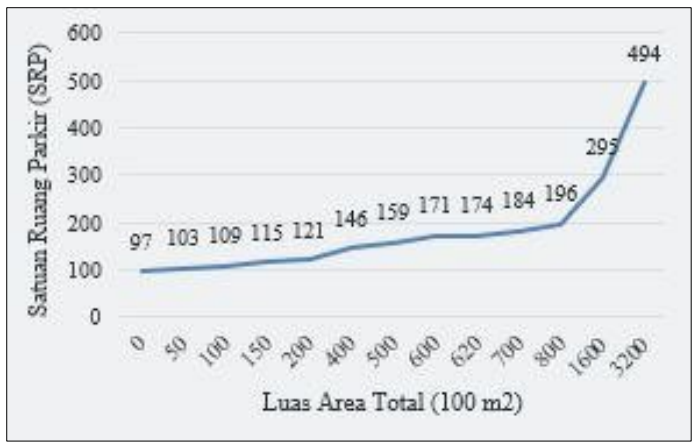

Gambar 7. Kebutuhan Ruang Parkir

Dapat dilihat dari grafik tersebut, bahwa kebutuhan ruang parkir kawasan Situ Gede sebesar 174 SRP. Apabila dari 174 SRP tersebut diasumsikan kedalam jumlah kendaraan dan dalam satuan $\mathrm{m}^{2}$ seperti pada tabel 11 berikut:

Tabel 5. Satuan Ruang Parkir Dalam $\mathrm{m}^{2}$

\begin{tabular}{clccc}
\hline No & $\begin{array}{c}\text { Jenis } \\
\text { Kendaraan }\end{array}$ & SRP $\left(\mathrm{m}^{2}\right)$ & $\begin{array}{c}\text { Jumlah } \\
\text { Kendaraan (unit) }\end{array}$ & $\begin{array}{c}\text { Luas } \\
\left(\mathrm{m}^{2}\right)\end{array}$ \\
\hline 1 & $\begin{array}{l}\text { Motor } \\
\text { (MC) }\end{array}$ & $0.75 \times 2$ & 108 & 162 \\
2 & $\begin{array}{l}\text { Kendaraan } \\
\text { Penumpang }\end{array}$ & $3 \times 5$ & 54 & 810 \\
3 & $\begin{array}{l}\text { Bus (HV) } \\
\text { Mu }\end{array}$ & $3.4 \times 12$ & 12 & 490 \\
\hline
\end{tabular}

Sumber : Hasil analisis, 2020 
Rencana gedung parkir yang akan dibuat diintegrasikan dengan pusat perbelanjaan (pusat oleh-oleh produk UMKM masyarakat Situ Gede dan sekitarnya, dan kebutuhan konsumsi pengunjung), serta diintegrasikan dengan kamar kost untuk memenuhi kebutuhan mahasiswa IPB yang letak kampusnya tidak jauh dari kawasan Situ Gede. Hal tersebut dilakukan karena mempertimbangkan biaya untuk pembuatan gedung dengan pendapatan dari gedung tersebut ketika sudah beroperasi. Apabila hanya dibuatkan gedung parkir saja, biaya pembuatan gedung cukup mahal dan pendapatan dari parkir hanya sedikit. Dengan ketentuan perencanaan gedung sebagai berikut :

a. Data Teknis :

- Fungsi bangunan : tempat parkir, pusat perbelanjaan, dan hunian.

b. Data Bangunan :

- Jumlah lantai : 5 (lantai 1 \& 2 untuk parkir, lantai 3 pusat perbelanjaan, dan lantai 4-5 untuk hunian).

- Tinggi tiap lantai : lantai dasar $5 \mathrm{~m}$, lantai 2-5 memliki ketinggian $3 \mathrm{~m}$.

- Jarak antar kolom : $6 \mathrm{~m}$.

- Tebal pelat lantai : 0,16m.

- Lebar gedung : $30 \mathrm{~m}$.

- Panjang gedung : $54 \mathrm{~m}+4 \mathrm{~m}$ untuk ramp parkir.

Ilustrasi gedung parkir terintegrasi tersebut dapat dilihat pada beberapa gambar berikut ini:

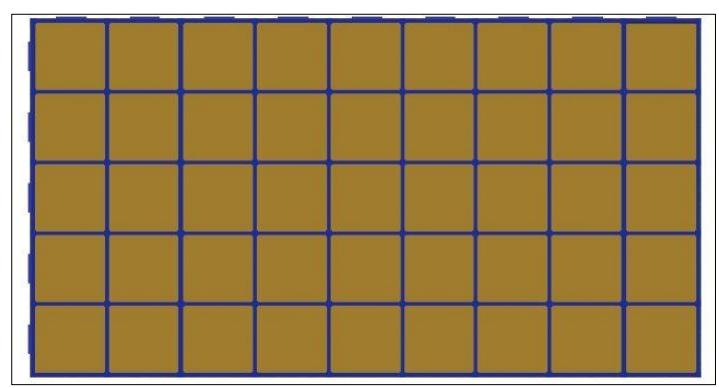

Gambar 8. Gedung Tampak Atas
Pada gambar 8 tersebut memperlihatkan bagian gedung tampak atas dengan bagian atap dihilangkan, sehingga terlihat bagian struktur balok, kolom, dan lantai dari gedung. Bagian gedung palingatas ini merupakan bagian hunian yang ditujukan untuk wisatawan maupun sebagai tempat kost mahasiswa. Setiap kamarnya memiliki ukuran $6 \times 6$ $\mathrm{m}$, yang dapat diisi 2-3 orang per kamar. Gambar berikutnya merupakan tampak depan dari gedung. panjang gedung $54 \mathrm{~m}$ dan ketinggian mencapai $17 \mathrm{~m}$.

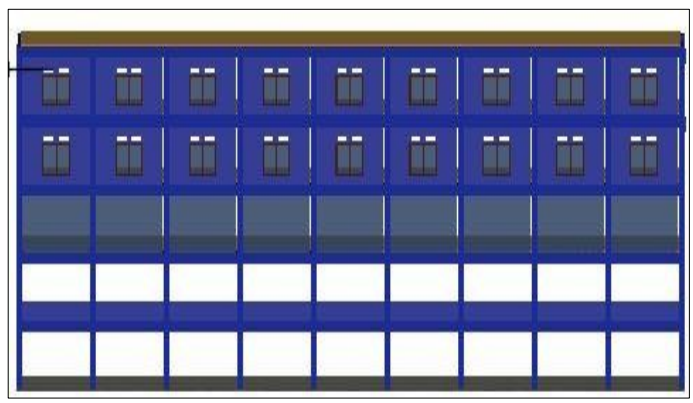

Gambar 9. Gedung Tampak Depan

Seperti yang dijelaskan sebelumnya, bahwa pembagian lantai gedung berdasarkan fungsi yang berbeda. Gedung lantai 1 dan 2 digunakan untuk parkir yang dapat menampung 174 SRP dengan rincian kendaraan yang tertampung setiap jam sebanyak 54 unit mobil, 108 unit sepeda motor, dan 12 unit bus/truk. Gedung lantai 3 digunakan sebagai pusat perbelanjaan, sedangkan lantai 4-5 digunakan sebagai hunian/kamar kost mahasiswa.

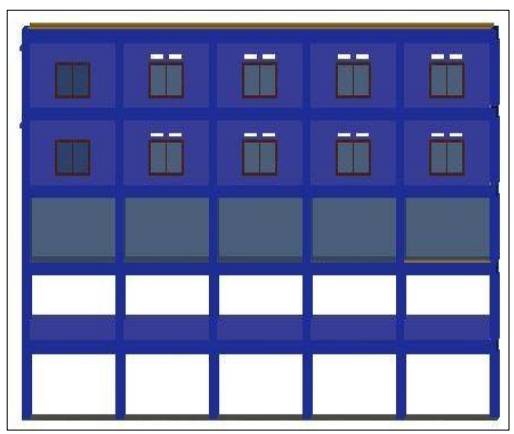

Gambar 10. Gedung Tampak Samping 
Gambar di atas merupakan gedung apabila dilihat dari samping, lebar gedung tersebut adalah $30 \mathrm{~m}$ dengan jarak $6 \mathrm{~m}$ untuk setiap kolomnya. Ketinggian lantai 1 yaitu $5 \mathrm{~m}$, sedangkan ketinggian lantai 2-4 yaitu $3 \mathrm{~m}$. Hal tersebut dikarenakan lantai 1 digunakan sebagai tempat untuk parkir kendaan high volume (HV) seperti bus dan truk, yang maksimal tinggi kendaraannya mencapai 4,2 m. Sehingga apabila diberikan ketinggian lantai sebesar $5 \mathrm{~m}$ masih ada ruang untuk tinggi jagaan.

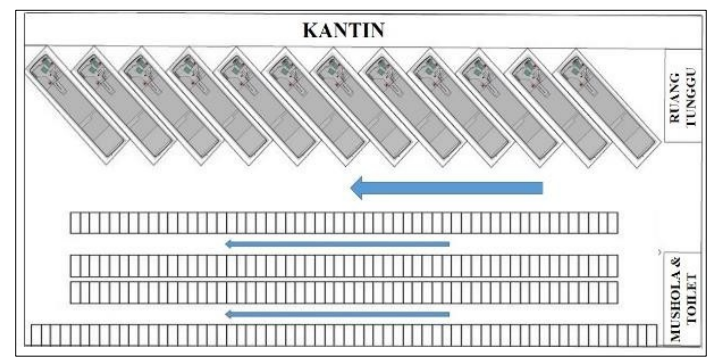

Gambar 11. Gedung Parkir Lantai

Gedung lantai 1 diperuntukkan sebagai tempat parkir jenis kendaraan high volume seperti bus dan truk dan sepeda motor. Kapasitas rencana lantai 1 tersebut dapat diisi bus/truk sebanyak 12 unit pada satu waktu, dan 108 unit sepeda motor pada satu waktu. Panah warna biru menunjukkan jalur masuk dan keluar kendaraan, terdapat ruang kosong cukup lebar untuk memberi jarak antara tempat parkir bus dan sepeda motor. Ruang tersebut dapat digunakan sebagai jalur masuk dan keluar dari bus/truk. Pada lantai 1 tersebut juga dilengkapi dengan beberapa fasilitas pendukung seperti mushola, toilet, ruang tunggu, dan kantin. Hal tersebut guna memberikan kenyamanan bagi pengunjung maupun bagi sopir yang menunggu rombongan. Ruang tunggu, mushola, dan toilet ditempatkan di bagian pintu masuk agar memudahkan pengunjung dalam mencari fasilitas tersebut.

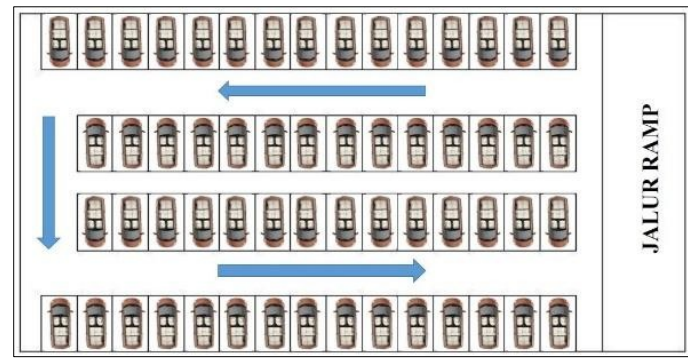

Gambar 12. Sketsa Gedung Parkir Lantai 2

Pada bagian lantai 2 gedung parkir tersebut diperuntukkan bagi jenis kendaraan mobil penumpang, dengan kapasitas lantai dapat menampung sebanyak kurang lebih 54 unit mobil penumpang pada satu waktu.

Berdasarkan perhitungan rencana anggaran biaya (RAB), pembangunan gedung tersebut membutuhkan dana sekitar 8,1 miliar rupiah. Kemudian, dari hasil perhitungan perkiraan pendapatan dari gedung tersebut apabila telah beroperasi setiap tahun dapat menghasilkan 3 miliar rupiah. Sehingga perlu waktu sekitar 3 tahun untuk mendapat keuntungan dari pembangunan gedung tersebut.

\section{Peta Perencanaan Prasarana Kawasan Ekowisata Situ Gede}

Peta perencanaan ini merupakan peta yang dibuat dari hasil identifikasi prasarana eksisting, dan disesuaikan melalui perencanaan prasarana hasil evaluasi. Peta perencanaan ditunjukkan pada gambar 13, peta tersebut merupakan solusi yang ditawarkan untuk permasalahan yang terjadi di Situ Gede, seperti permasalahan akses keluar masuk wisata yang tidak hanya digunakan untuk Situ Gede, melainkan untuk menghubungkan ketiga situ yang ada di kawasan tersebut yaitu Situ Gede, Situ Leutik, dan Situ Panjang. 


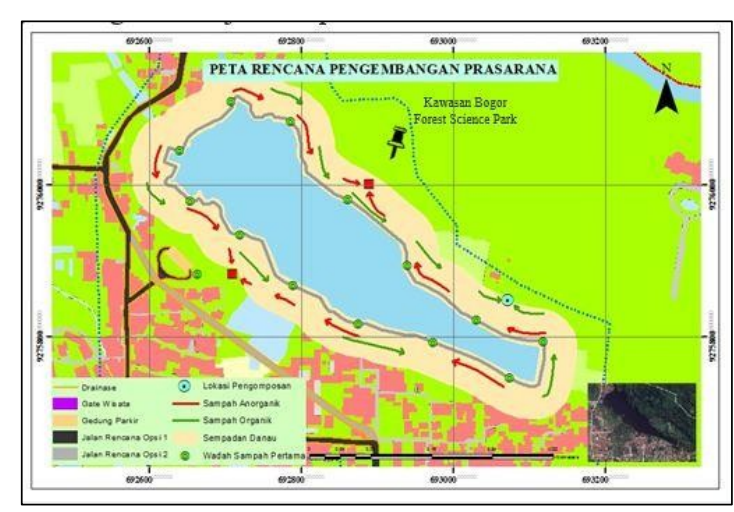

Gambar 13. Peta Rencana Prasarana

Apabila pelebaran jalan dirasa tidak memungkinkan, maka terdapat 2 pilihan alternatif yaitu dengan menambah jalan baru tapi resikonya terdapat pada biaya, dan alternatif kedua yaitu pemberlakuan jalan satu arah. Kemudian, jalan dilengkapi dengan drainase di pinggirannya untuk menghindari banjir. Saluran drainase disarankan menggunakan tutup beton, sehingga aman digunakan untuk pejalan kaki. Saluran drainase dilengkapi dengan unit pemantau sedimen.

Pada kedua prasarana yang di evaluasi yaitu jalan, dan tempat parkir dilakukan pengembangan seperti yang dijelaskan sebelumnya. Prasarana jalan eksisting dengan lebar kurang dari 5 meter dilakukan pelebaran dan ada perubahan trase jalan pada beberapatitik. Perubahan trase jalan tersebut dikarenakan penerapan batas sempadan danau untuk memaksimalkan fungsi konservasi dan kawasan lindung dari danau tersebut. Jalan yang direncanakan terbagi menjadi beberapa bagian yaitu damaja (daerah manfaat jalan), dawasja (daerah pengawasan jalan), dan penempatan utilitas. Tipe jalan yang direncanakan 2 lajur 2 arah tidak terbagi, dengan lebar lajur 3,6 m. Jalan rencana juga dilengkapi dengan bahu jalan sebesar $0,5 \mathrm{~m}$, dan trotoar sebesar $1,5 \mathrm{~m}$. Dalam mengurangi limpasan dari air hujan, direncanakan drainase memiliki dimensi tinggi $1,02 \mathrm{~m}$ dan lebar $0,77 \mathrm{~m}$ yang dilengkapi dengan indikator pemantau sedimen. Prasarana terakhir yang dievaluasi yaitu tempat parkir, dimana tempat parkir awal yang hanya $17 \mathrm{~m} \times 10 \mathrm{~m}$ di lahan terbuka digantikan dengan tempat parkir berupa gedung. Gedung parkir direncanakan memiliki 174 SRP (Satuan Ruang Parkir), atau dengan kendaraan rencana yang dapat parkir pada satu waktu yaitu 108 buah sepeda motor, 54 buah mobil, dan 12 buah bus/truk. Gedung parkir direncanakan dibangun dua lantai, dengan lantai pertama untuk kendaraan bus, dan lantai atas untuk motor dan mobil.

\section{KESIMPULAN}

Dari hasil pembahasan diatas dapat diambil beberapa kesimpulan yakni sebagai berikut :

1. Pemanfaatan Situ Gede sebagai kawasan wisata belum optimal, dikarenakan prasarana pendukung seperti jalan, sistem pengelolaan persampahan, dan tempat parkir belum memadai. Sehingga diperlukan perencanaan tiga prasarana utama tersebut.

2. Penataan zonasi dilakukan guna memberi perlindungan, penggunaan, dan pengendalian sumberdaya yang ada di Situ Gede terutama pembuatan sempadan danau selebar $50 \mathrm{~m}$ dari badan situ.

3. Jalan lingkungan direncanakan memiliki ukuran lebar $7 \mathrm{~m}$ dengan 2 lajur 2 arah tidak terbagi, serta dilengkapi bahu jalan selebar 0,5 m dan trotoar dengan lebar $1.5 \mathrm{~m}$.

4. Gedung parkir terintegrasi direncanakan 5 lantai memiliki kapasitas 174 SRP, dengan rincian 108 SRP sepeda motor, 54 SRP kendaraan penumpang, dan 12 SRP bus/truk. Luas lahan yang dibutuhkan gedung parkir rencana adalah 1.620 
$\mathrm{m}^{2}$.

\section{DAFTAR PUSTAKA}

Agusbushro R, Makarau VH, Sembel A. 2015. Analisis kebutuhan prasarana dan sarana pariwisata di Kawasan Taman Nasional Bunaken Kecamatan Bunaken Kepulauan Kota Manado[skripsi]. Manado (ID): Universitas Sam Ratulangi Manado.

[BPSDA] Badan Pengelolaan Sumberdaya Air Kota Bogor. 2008. Pengelolaan Sumberdaya Air. Bogor (ID) : Departemen Pekerjaan Umum.

[BSN] Badan Standardisasi Nasional. 2004. Tata Cara Perencanaan Lingkungan Perumahan di Perkotaan. SNI 03-1733-2004. Jakarta (ID): Badan Standardisasi Nasional.

[BSN] Badan Standardisasi Nasional. 2004. Geometri Jalan Perkotaan. RSNI T-14-2004. Jakarta (ID): Badan Standardisasi Nasional. [DirjenPD] Direktorat Jenderal Perhubungan Darat. 1996. Pedoman Teknis Penyelenggaraan Fasilitas Parkir. Keputusan Dirjen Perhubungan Darat nomor 272/HK.105/DRJD/96. Jakarta (ID): Direktorat Jenderal Perhubungan Darat.

Hatmoko W, Triweko RW, Yudianto D. 2012. Sistem pendukung keputusan untuk perencanaan alokasi air secara partisipatoris pada suatu wilayah sungai. Jurnal Teknik Hidrolik. 3(1): 71-86.

Hijriati E, Mardiana R. 2014. Pengaruh ekowisata berbasis masyarakat terhadap perubahan kondisi ekologi, sosial dan ekonomi di Kampung Batusuhunan,
Sukabumi. Jurnal Sosiologi

Pedesaan. 2(3): 146-159.

[PemkotBogor] Pemerintah Kota Bogor. 2011. Rencana Tata Ruang Wilayah Kota Bogor 2011-2031. Peraturan Daerah Kota Bogor nomor 8 Tahun 2011. Bogor (ID): Sekretariat Kota Bogor.

[PermenPUPR] Menteri Pekerjaan Umum dan Perumahan Rakyat. 2015. Peraturan Menteri Pekerjaan Umum dan Perumahan Rakyat. Nomor 28/PRT/M/2015 Tentang Penetapan Garis Sempadan Sungai dan Garis Sempadan Danau. Jakarta (ID). Menteri Pekerjaan Umum dan Perumahan Rakyat.

[PRI] Pemerintah Republik Indonesia. 2004. Undang-undang Republik Indonesia Nomor 38 Tahun 2004 Tentang Jalan. Jakarta(ID). Sekretariat Negara.

Satria D. 2009. Strategi pengembangan ekowisata berbasis ekonomi lokal dalam rangka program pengentasan kemiskinan di wilayah kabupaten malang. Journal of Indonesian Applied Economics. 3(1): 37-47.

Sadewa T, Sutoyo. 2018. Kajian sistem drainase di daerah Jalan Pemuda, Kota Bogor. Jurnal Teknik Sipil dan Lingkungan. 3(3): 117-126

Widyanigsih P. 2015. Penilaian ekonomi Situ Gede, Kelurahan Situ Gede, Kecamatan Bogor Barat, Kota Bogor[skripsi]. Bogor (ID): Institut Pertanian Bogor. 